\title{
Artificial Intelligence Tools and Case Base Reasoning Approach for Improvement Business Process Performance
}

\author{
Aleksandar Vujovic, Zdravko Krivokapic and Jelena Jovanovic
}

Additional information is available at the end of the chapter

http://dx.doi.org/10.5772/46082

\section{Introduction}

Contemporary and every day more perfect information achievement, becomes available for everybody, and simply, very quickly become a necessity. It is necessary that organizations use information technology as a tool for developing a sense of learning, acquire and use knowledge. Information tools should not be use like tools for automation of existing processes. There should be another aspect or already obsolete category. With this aspects, thinking and attitudes, it can be said that we living in the century of knowledge and that we have already overcome period of information technology which should be, simply, implemented like support in the way for achieving knowledge.

This informational environment has been recognized in the world and because of there are significant rising in the use of artificial intelligence tools. There is evidence that is a great number of eligible to use and easily available software for needs of the development of such as systems in the field of artificial intelligence. Also, in [1] states that investment and implementation of artificial intelligence show significant results, particularly in attempt of to get higher profit. The artificial intelligence, like the word itself says is the area that deals with the development of systems that mimic human intelligence and a man with tend to replace him in some activities based on knowledge. That is way for over viewing problem of human absence, cost of services, disinclination of people to provide knowledge and similar. Specified conditions, particularly from the standpoint of the necessities of knowledge, and also the fact that in area of research topic for the purposes of quality management systems, there are evident gap [2, 3-10, 11]. That facts justifying the author's striving to be in this research and accept to use artificial intelligence tools for developing systems oriented to knowledge. These views and attitudes were in agreement: that there is no correct programming software that has a strong base of knowledge that could assist in 
identification of a problem, that has not developed a single expert system that deals with the measurement, evaluation, corrective and preventive action to improve organizational performance and the like $[12,13-16,10]$. It is also an incentive to be based on such analogies create a foundation set up and entered the field of artificial intelligence in order to obtain knowledge as one of the most important factors for creating competitiveness in the market $[17-19,20]$.

Everything above can be understand like introduction for developing an research whit main aim for developing a system in the field of artificial intelligence that would be based on the analysis in the quality management system and that has given recommendations for achieving business excellence and improve the financial performance of the organization. The main parts and activities of that research stay in the basis of this chapter.

\section{The main targets, methods and contribution}

Based on the introduction and results of researching literature source and practice, in the scope of this research, it can be set up main targets, and that are:

- to find (regardless of size or type of organization) area in organization which have priority from the standpoint of improvement,

- to establish new concept of Degree of Readiness and Coefficient of Significance which can show intensity and type of action which should be provide in direction of achieving business excellence and

- to develop and testing in real condition an expert system for improvement business process performances even those of financial character base on analogy with human body function.

In this sense, it can be use science method for inductive and deductive way of deciding and concluding. First one was used for collecting, estimating and analyzing of experimental data, or to making general knowledge by using specific knowledge and particular facts. The second one was used for applying and checking specific conclusion in real condition.

Also, like science approaches it was used: analogy method, expert decision and "ex post facto" or previous case and facts.

Beside that, many other methods and tools were conducted like: knowledge discovery in data base, data mining, case base reasoning-CBR, object oriented programming, artificial intelligence tools, Analytic Hierarchy Process-AHP, expert choice, testing in real condition, Visual Basic and Select Query Language.

Through a detailed analysis of literature sources and software, it was found evident gap in applying artificial intelligence tools for improvement business process performances based on Quality Management System-QMS and especially in experience of other and case reasoning. In this research, analogy between human body function and process oriented organization were established, and areas in organization which is prior from the standpoint of improvement were identified. Two unique data bases and significant number of company and data, make original experimental value and bases for research. Also, new concept of 
Degree of Readiness and Coefficient of Significance for achieving business excellence stay in the basis of new expert system for achieving business excellence. By applying this expert system, especially on prior area, employees should drive they process performances to excellent condition, even those of financial character. Also, many actions for improvement with appropriate coefficients which show theirs intensity where found. This action should be understood also like preventive action for strengthening organizational condition to avoid some failure in the system. This expert system was tested in real conditions in one very successful organization which will be participant in competition for European Award for business excellence. This test and verification showed that the system could be useful and also the efficient and effective

\section{Experimental research, areas for research and reasons for developing expert systems}

The basic facts of this research are attempted to define two levels of experimental data. The first level of the data is related to quality management systems and nonconformities that have emerged. This is a basic level of data which reflects the situation in the quality management systems and identify critical places that are subject to improvement. The base of these data is unique and consists of the 1009 nonconformities (cases), identified in over than $\mathbf{3 5 0}$ organizations. If we know that in our area in the field of competent certification body has, approximately 500 certificates, then the number of 350 is about $\mathbf{7 0} \%$ of the total number. That fact points out to the significance of sample for analysis.

The term nonconformities refer to any non-conformance of requirements of ISO 9001, nonconformity non-fulfilment of a requirement [21]. During the external audits of quality management system, competent and trained auditors can identify several types of nonconformities (Figure 1). We are using most significant data from highest level of pyramid at which were collected at the level of many country like external estimation and evaluation of they performance and condition.

Distribution of nonconformities depends on the rules that define the certification body itself. However, for the purposes of this research is used classification which is the most common in the literature, which is favour by the authoritative schools in the world in the field of management system and that is clearly recommended by European guidelines in the subject area, which is split into three levels. The first level is the disagreements that are evaluated as insignificant deviations from the standards and requirements which are interpreted as an oversight or random error. The other two categories are interpreted as nonconformities that represent a great deviation from the essential requirements, which are reflected in the frequent discrepancies in individual requirements, representing a deviation that brings into doubt the stability of the management system and threatening the operations of the organization.

Data base of nonconformities which is under consideration in this research contains only nonconformities in the domain of the other two categories, and that giving greater importance to this research and gives greater significance results. 


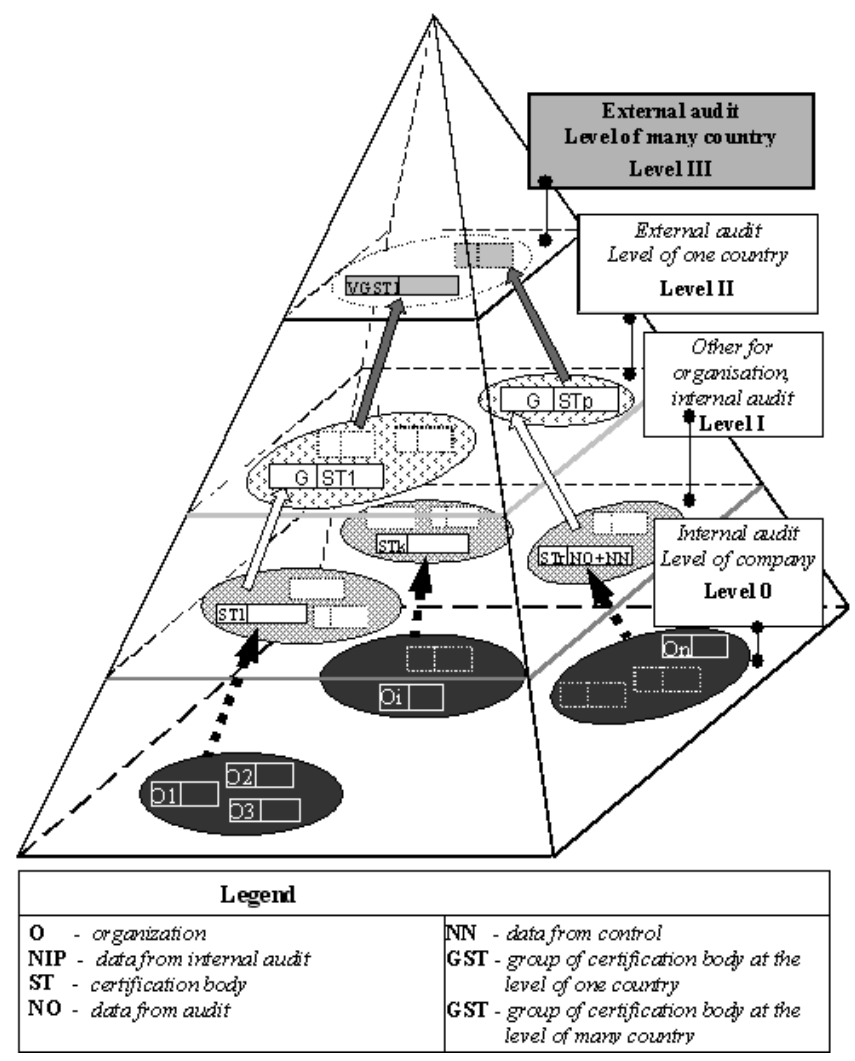

Figure 1. Data source (highest level of data significance)

Non-conformances are identified in accordance with the structure requirements defined in the ISO 9001 standard as follows:

- Quality management systems: 4.1 general requirements, 4.2 documentation requirements,

- Management responsibility (module 5): 5.1 management commitment, 5.2 customer focus, 5.3 quality policy, 5.4 planning, 5.5 responsibility, authority and communication, 5.6 management review,

- $\quad$ Resource management (module 6): 6.1 provision of resource, 6.2 human resources, 6.3 infrastructure, 6.4 work environment,

- $\quad$ Product realization (module 7): 7.1 Planning of product realization, 7.2 customer related processes, 7.3 design and development, 7.4 purchasing, 7.5 production and service provision, 7.6 control of monitoring and measuring devices,

- Measurement, analysis and improvement (module 8): 8.1 general, 8.2.1 customer satisfaction, 8.2.2 internal audit, 8.2.3 monitoring and measurement of processes, 8.2.4 monitoring and measurements of product, 8.3 control of nonconforming product, 8.4 analysis of data, 8.5 improvement. 
Accordingly, for example in the field of 8.2.1 from the standpoint of the appearance of nonconformances organizations have a significant and frequent or large deviations in the sense that it does not follow the information about the observations of users, it did not define the methods for obtaining this information, they do not have strong communication with customers and similar. Or for example in the field of 8.2.3 with the observed aspect, organizations do not apply appropriate methods for monitoring and performance measurement processes, have not mechanisms for implementation of corrective measures in cases that have not achieved the planned performance of processes and the like.

This data will be used like the basis of CBR approach or approach where it is possible to make significant conclusion in the sense of main target of this research. This approach is shown in figure 2 .

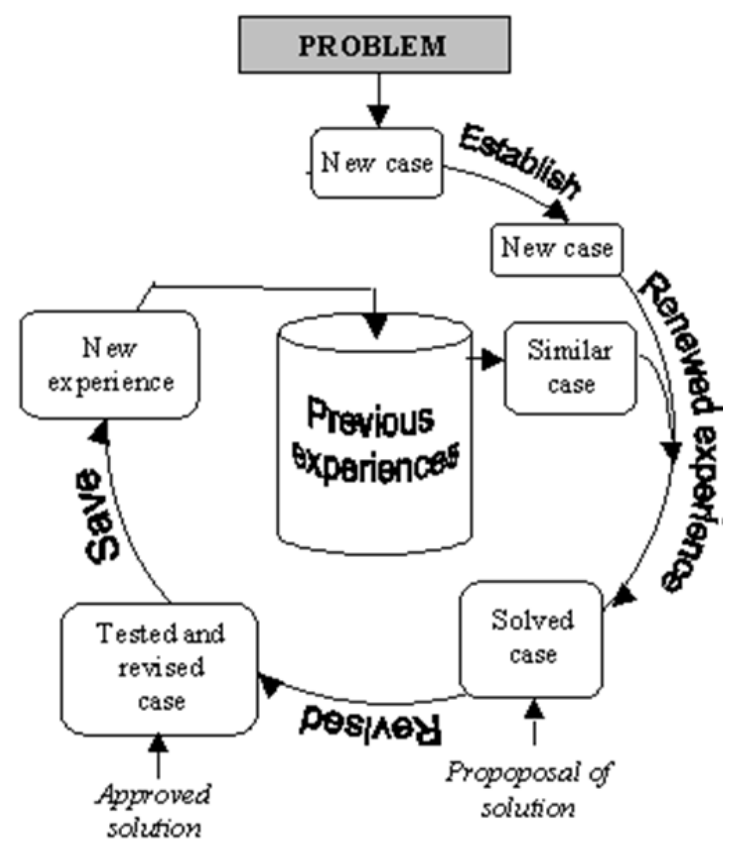

Figure 2. Case based approach

The second level of data consist data from evaluation organizations that participated in the competition for the quality award based on European Quality Award criteria. This database is unique, as well as in the previous case. Data were transferred in encoded form in order to secure the identity of the organization. Data were collected in $100 \%$ extent (34 organizations) and thus are significant and give a real picture of the situation in our organizations. These data are used for comparison with previous, basic level data. That is way for making improvement or exalt from basic level on the level of business excellence and way for making knowledge which reproduce expert system on his output. That is also comply with literature more existent attitude, and natural way that organization should first implement 
Quality Management System and after that system which is based on Total Quality Management concept [22, 23-26, 27].

In order to show the current directions and trends in the field of development of software for quality, and to select under researched areas in the field of software quality, it was conducted a detailed review and analysis of a total of 143 software. All necessities information for that analysis are available in site (http://www.qualitymag.com) where are publish updated software items which are related to quality. The results of the analysis are shown in the figure 3.

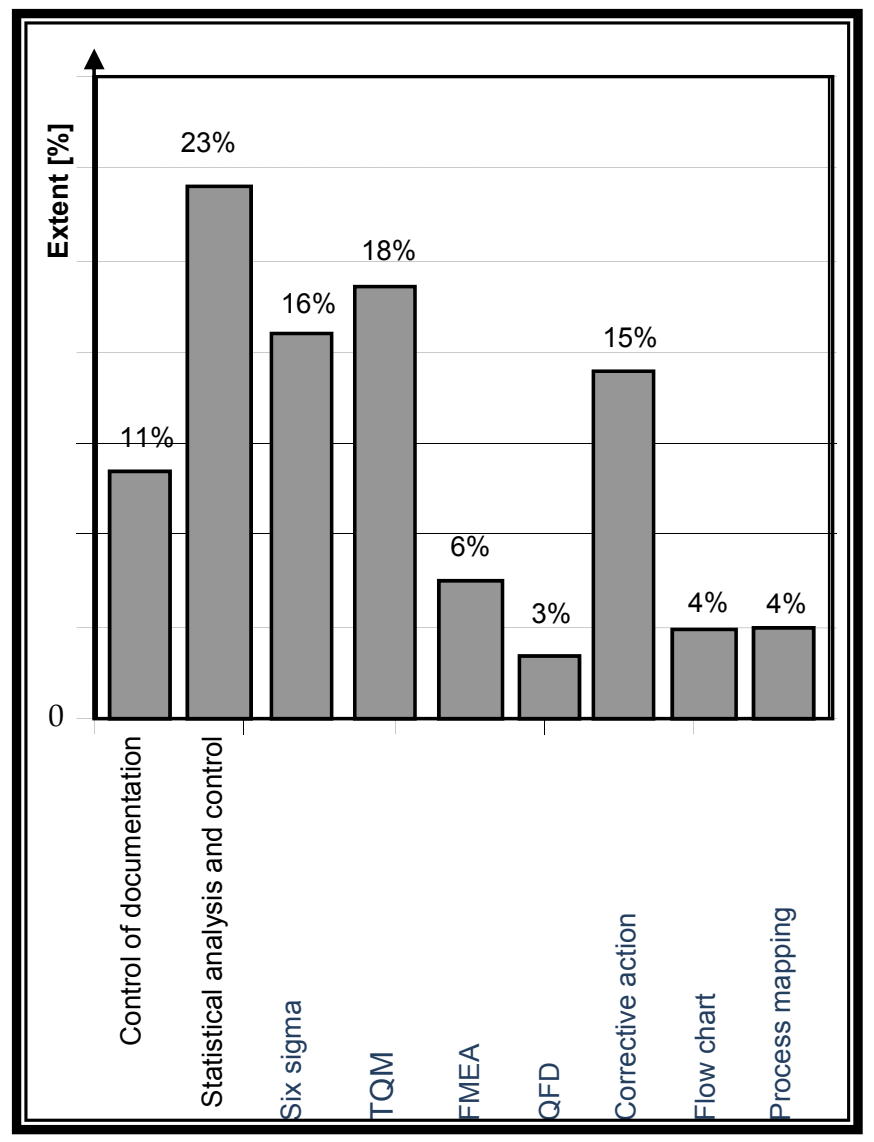

Figure 3. Results of analysis of existent software for quality

On the $x$ axis diagrams are shown the software ability and orientation. Obviously is that the software in the field of quality is usually oriented to the control of documentation, statistical control and analysis, six sigma model, concept of total quality management, FMEA and QFD methodology, corrective action, flowchart and process mapping. However, there are specific tools for automation: the implementation of the quality management system 
documentation, description of information flow, implementation methods and techniques of quality, and more. Therefore, it can be concluded that there is no software that is based on the application of artificial intelligence tools in the sense of the definition of preventive actions for the purpose of improving the process. The greatest number of software is related to the application of statistical methods in the process of monitoring and improving quality. It is obviously that a large number of software is based on total quality management systems concept. The facts point out present approach which we develop in this research and also justify further research in this area. It is interesting that a large number of software are base on the corrective actions and on the other hand there is not any registered software that has application for output preventive action what is, of course, main recommendation of ISO 9000 series. This fact also gives stimulus in terms of development of software that emphasis to the prevention. That approach is unique in the field of software for quality and makes this research more significant.

Beside this analysis, in this research were analyzed huge amounts of available books in order to point out the justification of applying expert system. Expert systems are different from other artificial intelligence systems in that, they attempt to explicitly and unequivocally embody expertise and knowledge with the software [28]. Expert systems are also identified as one of the most commercial branches and in most number of projects used artificial intelligence tools [29, 30]. For example, it is estimated that in the first half of 21st century, even $75 \%$ of all legal documents be written with the assistance of expert systems [31]. Also expert systems will be of vital importance for measuring the quality of products and services [32-34]. Expert systems are an area of special importance with rise trends in modern business conditions [35, 36-38]. They have special significance in a highly developed countries where is actual knowledge based economy. This research highlight trends, significance and justification of developing and implementing expert systems.

Main idea and approach for developing expert system come from analogy between human body functions and process in some organization which was organized based on process modelling from ISO 9000 respect. This approach is present on figure 4.

This research tries to deal with perfection of functioning of the human body compare with a process modelling structures of the implemented quality management system. The challenge made in this way, tried to create a system that is universal for all sizes of organization, which incorporates a large number of gathered data, in fact a large number of experiences, in order to get a better image of the system status. This should be added to the primary goal which is to develop a model for improvement of management system, oriented to achieve BE according to show off how to maintain and improve the performance of the human body. However, the goal is also, to develop a system for measuring performance and capacity of each activity in the QMS, in order to obtain a true picture of the systems and capabilities in order to define the areas where improvements should be made, with clearly defined intensity of improvement. On the basis, thus established the analogy is made to compare elements of implemented QMS to the systems that have applied for Quality award for BE as a system with high performance. 


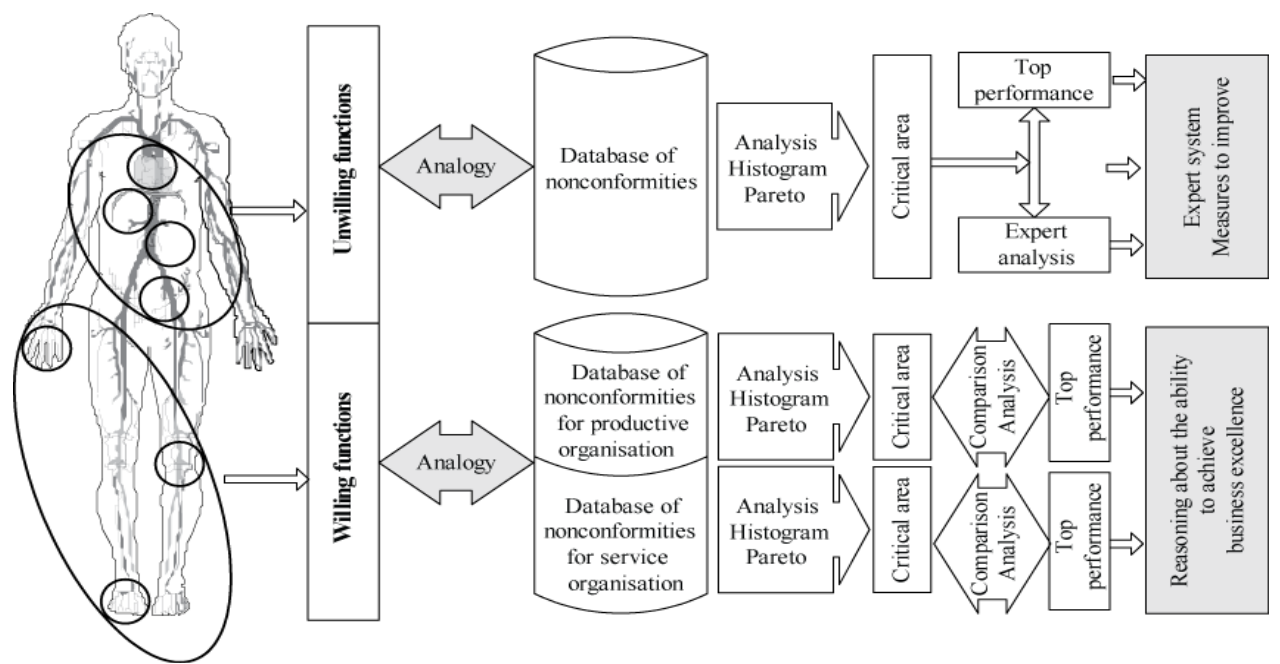

Figure 4. Analogy with the human organism in order to improve organizational performance

To establish the analogy between the process modulated organizational structure and the human organism, so as to create the system that is independent from organizational functions and based only on the process model, following division of man functions was made $[39,40]$ :

- willing and

- unwilling functions.

Willing functions (term "functions" is used in medical terminology, although it is equally correct, to use a term "activities" in view of ISO 9000 standard terminology. For reasons of consistent referencing and use of theories from the field of medicine, the author has chosen to use the term functions.) are those dependent on man's profession and performed by man's will. They are variable and dictated by a central control of the organism. For example, when a worker at the construction site lifts his hand, it is not the same as when a referee at the game lifts his hand and etc. Willing functions refer to functions of external motoric organs.

Second category is made of unwilling or automated functions and their use is given by their existence. There are functions that are same in all professions and all people (considering that they exist, i.e. that human body is in good health) and do not depend on the man will but are simply executed. For example, those are functions of secreting enzymes, hormones, heartbeats, and similar, like ordinary body functions, and functions that cannot be controlled [41, 42].

With such a ratio of functions in the human body, we can establish the analogy of the system with implemented quality management system. Analogy in term of willing function goes in direction to developed all data in to two category, production and service organization and make some analyses, which is not subject of this research. 
In order to meet requirements of this research, only analogy in terms of unwilling functions has been considered. The idea is to use all nonconformities (undependable of organization type or size) and base on case base reasoning approach, make conclusion about readiness of systems to making some top form.

\section{Approach to developing expert system}

At the market today, we can find many tools for creating expert systems. These systems can be developed in a programmable environment through tools of type $\mathrm{C}++$, Visual Basic or some other programs which are related to development of expert systems. However, today are developed specialized tools for creating expert systems which allow a high degree of automation in process of developing expert systems. There are called expert system shells. From the standpoint of this research it was carried out choice of expert system shell from the aspect of next four criteria [43-45, Personal communication with group for consulting from London South Bank University, Business, Computing \& Information Management, 2011):

- programmability,

- comprehensiveness,

- universality,

- price.

During the election, it was analyzed 58 shells. All information about shells are available on the Internet [2], and classified in a group of commercial shell. Detailed analyses were conducted separately for each tool through analyzing belonging site. For evaluation on the basis of the criteria it was adopted the scale of 1 to 5 where 1 is unsatisfactory grade. According to defined criteria as a most distinguished tool for the needs of the research was adopted ACQUIRE shell. That tool is non programming oriented and it has affordable price. This is a tool that supports the work of the Windows operational environment. It has possibility to develop all elements of expert system and supports forward, backward and combined chaining. For the presentation of knowledge it can be used production rules, the action table, or combined techniques. During a process of developing expert system, the role of engineer for knowledge took up first author, and the role of one expert took up second author. Also, as sources of knowledge were used following:

- experience from eleven prestigious organizations in the world of field of quality management systems, business excellence and organizational performance [46],

- guidelines from standards for improving organizational performance [47 ],

- $\quad$ best practices from auditing of ISO 9001 oriented system [48],

- experience and practice of organizations that participated in the competition for the Oscar of quality award [49],

- $\quad$ theory and principles of TQM [50],

- experiences that are listed in [51] and indicate the path to business excellence.

The expert systems are included and knowledge gained through many concrete practical projects of quality management systems implementation, and many training on that topic. That knowledge is next: 
- knowledge that are specific to certain companies,

- knowledge derived from specific experiences and on specific way of solving problem,

- knowledge of those that are best for certain jobs and are passed special training,

- knowledge of those that is proven in practice for the specific job and similar.

For the purposes of this research, expert system was develop for modules 5 (management responsibility) and module 8 (measurement, analyses and improvement) of ISO 9001 standard. The reason for that is that these areas have the greatest importance in achieving business excellence [1] and therefore they should be considerate from the standpoint of improvement. Also, another reason is that module 8 has requirements that are oriented to the improvement and that is essence and priority.

The idea of this research is to make the integration of decision support systems (DSS) which is operate on first level of experimental data, and expert system. That is modern approach of integration a number of tools with the aim of acquiring a larger volume of better knowledge [52] and make system with higher level of intelligence. Today trends are integration expert systems and traditional decision support systems which as output give data and information [53].

Integration of expert systems and decision support system can be achieved in two ways [54]. The purpose of this research is to use model which is present on figure 5 . based on the collection and analysis of data obtained at the output of the decision support system and it provide important information like one of inputs for expert system and its knowledge base. This is the model which is completely compatible with previous remarked analogy with human body. This two approach stay in base of this analogy integrative model for improvement business process performance.

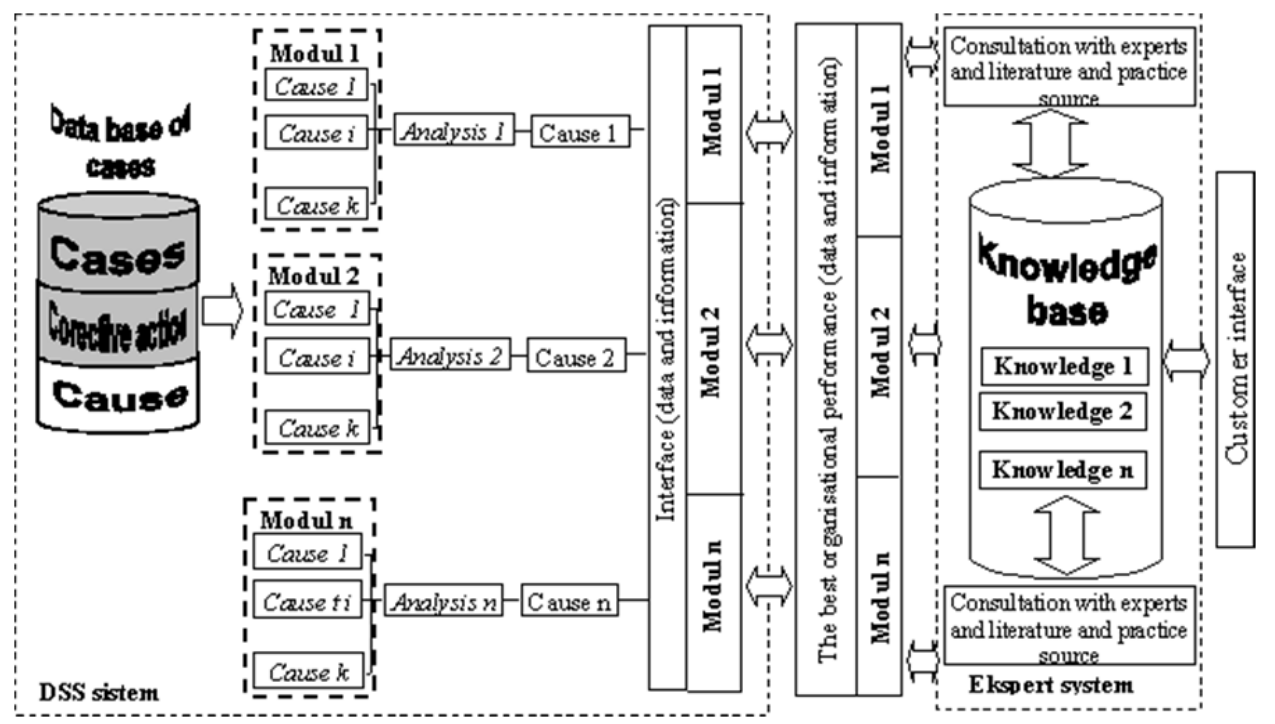

Figure 5. Integrative approach for merging expert system like separate part of DSS components 
For the purposes of this research, we developed a decision support system in the MS Access, Select Query Language and Visual Basic environment. This system is base on the first level of experimental data, and like one of outputs it gives results which are present on figure 6 (for module 8).

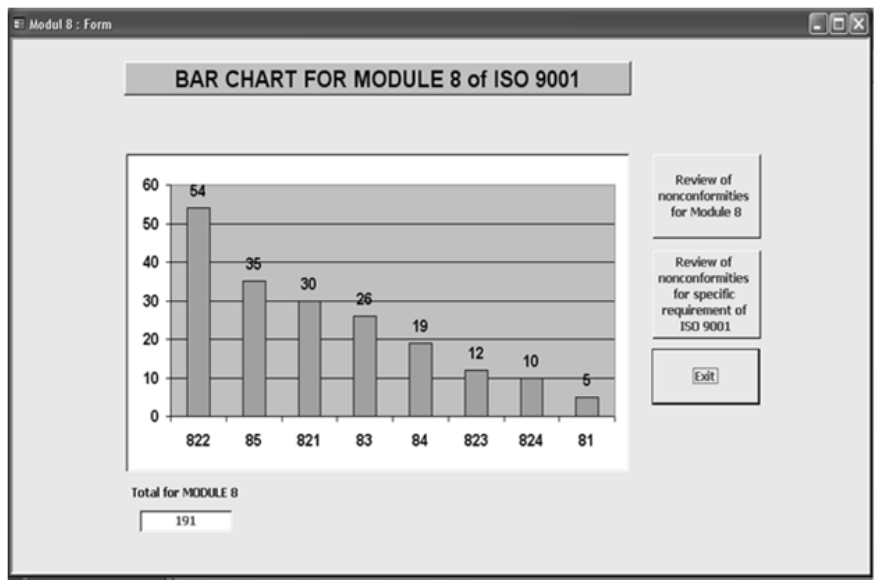

Figure 6. Results of DSS systems for module 8-measurement, analysis and

Applying Pareto method and rules of $70 / 30$ it can be identified area which is crucial from the standpoint of improvement. Also, this system like support for making decision provides written presentation of nonconformities which can be shown as experience of other companies. That could be use like important data for the definition of knowledge in expert system. In addition, this system provides, and comparative analysis with the period of the four years before, which also has significance for the definition of knowledge in the expert system.

Connection between data from the first and data from the second level was achieved through the introduction of the concept of "Degree of readiness (Si)" in achieving business excellence, in accordance with the following expression:

$$
\mathrm{S}_{\mathrm{i}}=\mathrm{N}_{z}[\%] * K_{z}, \quad \mathrm{i}=1,2, \ldots, 26
$$

where:

Si Degree of readiness for all type of organizations for all requests of ISO 9001

$\mathrm{Nz} \quad$ Power of a standard clause in terms of percentage. $\mathrm{Nz}=f$ (number of nonconformities from experimental database)

$\mathrm{Kz} \quad$ Coefficient of significance for achieving business excellence

That degree is applies to every single request of ISO 9001 and showing the willingness or the ability of organizations (both manufacturing and service sector) to attain business excellence in some areas. To find this degree, we are using method Analytic Hierarchy Process (AHP) and corresponding software Expert Choice. Results are shown in table 1. 


\begin{tabular}{|c|c|c|c|c|c|c|c|}
\hline Requests & $\begin{array}{c}\text { Organization } \\
\text { (power) }\end{array}$ & $\mathrm{K}_{\mathrm{z}}$ & $\mathrm{S}_{\mathrm{i}}$ & Requests & $\begin{array}{c}\text { Organization } \\
\text { (power) }\end{array}$ & $\mathrm{K}_{\mathrm{z}}$ & $\mathrm{S}_{\mathrm{i}}$ \\
\hline $\mathbf{8 2 1}$ & 66.67 & 0.090 & $\mathbf{6 . 0 0}$ & 83 & 50 & 0.036 & 1.8 \\
\hline $\mathbf{8 2 3}$ & 50 & 0.075 & $\mathbf{3 . 7 5}$ & 52 & 40 & 0.035 & 1.4 \\
\hline $\mathbf{8 5}$ & 37.14 & 0.072 & $\mathbf{2 . 6 7 4}$ & 81 & 60 & 0.033 & 1.98 \\
\hline $\mathbf{8 4}$ & 57.9 & 0.066 & $\mathbf{3 . 8 2 1}$ & 822 & 46.3 & 0.032 & 1.481 \\
\hline $\mathbf{5 4}$ & 48.72 & 0.064 & $\mathbf{3 . 1 1 8}$ & 73 & 76.19 & 0.026 & 1.981 \\
\hline $\mathbf{8 2 4}$ & 40 & 0.064 & $\mathbf{2 . 5 6}$ & 61 & 100 & 0.022 & 2.2 \\
\hline $\mathbf{5 6}$ & 44 & 0.059 & $\mathbf{2 . 5 9 6}$ & 75 & 37.5 & 0.022 & 0.825 \\
\hline $\mathbf{5 3}$ & 70 & 0.054 & $\mathbf{3 . 7 8}$ & 64 & 63.64 & 0.019 & 1.21 \\
\hline $\mathbf{7 1}$ & 56.52 & 0.04 & $\mathbf{2 . 2 6}$ & 76 & 44.68 & 0.018 & 0.804 \\
\hline $\mathbf{4 1}$ & 65.22 & 0.038 & $\mathbf{2 . 4 7 8}$ & 62 & 62.07 & 0.008 & 0.496 \\
\hline $\mathbf{5 1}$ & 72.73 & 0.038 & $\mathbf{2 . 7 6 3}$ & 74 & 52.94 & 0.008 & 0.423 \\
\hline $\mathbf{7 2}$ & 56.76 & 0.038 & $\mathbf{2 . 1 5 7}$ & 63 & 50 & 0.005 & 0.25 \\
\hline $\mathbf{5 5}$ & 66.67 & 0.037 & $\mathbf{2 . 4 6 7}$ & 42 & 49.26 & 0.005 & 0.246 \\
\hline
\end{tabular}

Table 1. Review of the degree of readiness for all type organization in relation to every request of the standard

It is important to emphasize this because it was used and it is very important during definition of preventive measures in terms of defining their priorities and "power". Also, "power" of prevention was related with number of nonconformities in particular area. That means, larger number of nonconformities, or larger number of experience, make possibilities for defining more effective and efficient preventive action like output of expert system.

Through application of Pareto method, based on coefficient of significance following requests were identified as the most significant for achieving business excellence:

requests $\quad-821,823,85,84,54,824,56,53,71,41,51,72,55$

At the same time, this is important areas, and have high level of priority for improvement from the standpoint of achieving business excellence and it is very important for defining preventive action of expert system and intensity of that action. If we take a look at the list of "Coefficients of significance" for business excellence achieving, especially the most important ones and perform comparison with the list of variables and their significance in terms of: Business Process Reengineering (BPR), manufacturing strategy, benchmarking and performance measurement, being the result of the appreciated research [55] and [56] it may be found significant intercompatibility.

The concerned compatibility is especially reflected in the following variables, evaluated in the relative research as highly significant for the following four projects, i.e.: customer satisfaction, quality, employee satisfaction and personal growth, customer adaptability, identification of top managers with BPR goals, strong process orientation, results orientation, direct customer cooperation. On the other hand, the above mentioned four areas 
are considered as highly important for any market-oriented organization, thence it can be concluded that organizations by strengthening their capacities in areas of presented "Coefficients of significance" (especially the most important ones), are not only strengthened in terms of the business excellence achieving as per European Award model, but also in the stated four areas.

But some of these areas are much more important then other. Because that, the research was further elaborated in order to indicate most important area for improvement and area where should be focus attention and where should be provide very intensive action in order to achieve best organizational condition and results. This research was conduct from the standpoint of occurrence of nonconformities in all type of organisation regardless of they size or type (both for manufacturing and service organisation). Parallel the Pareto method (70/30) was carried out in that direction and based on that, it was identified next areas:

requests $\quad-56,75,62,822,74,76,54,72,85,821,55,63$

Now we are search for common requests (area) that are most important and where should be oriented focus and where should be provide extensively action in terms of achieving business excellence regardless of type or size of organization. And they are:

1. 821 - customer satisfaction,

2. 72 - customer related processes,

3. 54 - planning,

4. 85 - continual improvement,

5. $56-$ management review and

6. 55 - responsibility, authority and communication.

This area is most important for defining output of expert system and for defining intensity of action for improvement.

Objects were defined during the process of expert system developing. That were depend of problem which should be solved, base on ISO 9001 oriented check list an based on experience which can be find on DSS output. Base on results of DSS system, it is defined value of the object and relation between them. In that way, it is created decision tree, which is present on figure 7 .

At the end, after starting the program, in a short time, system introduce user in a set of dialog boxes. One of them is shown on figure 8 .

Depend on the answers, expert system produce user's report, like one which is presented on figure 9.

Data obtained from this report, user can use and implement knowledge that an expert system produces. However, users can improve performance of an organization in the field where such as performance are on lower level. Also, it can be improvement performances of other, non critical, area and can be reach level of business excellence. 


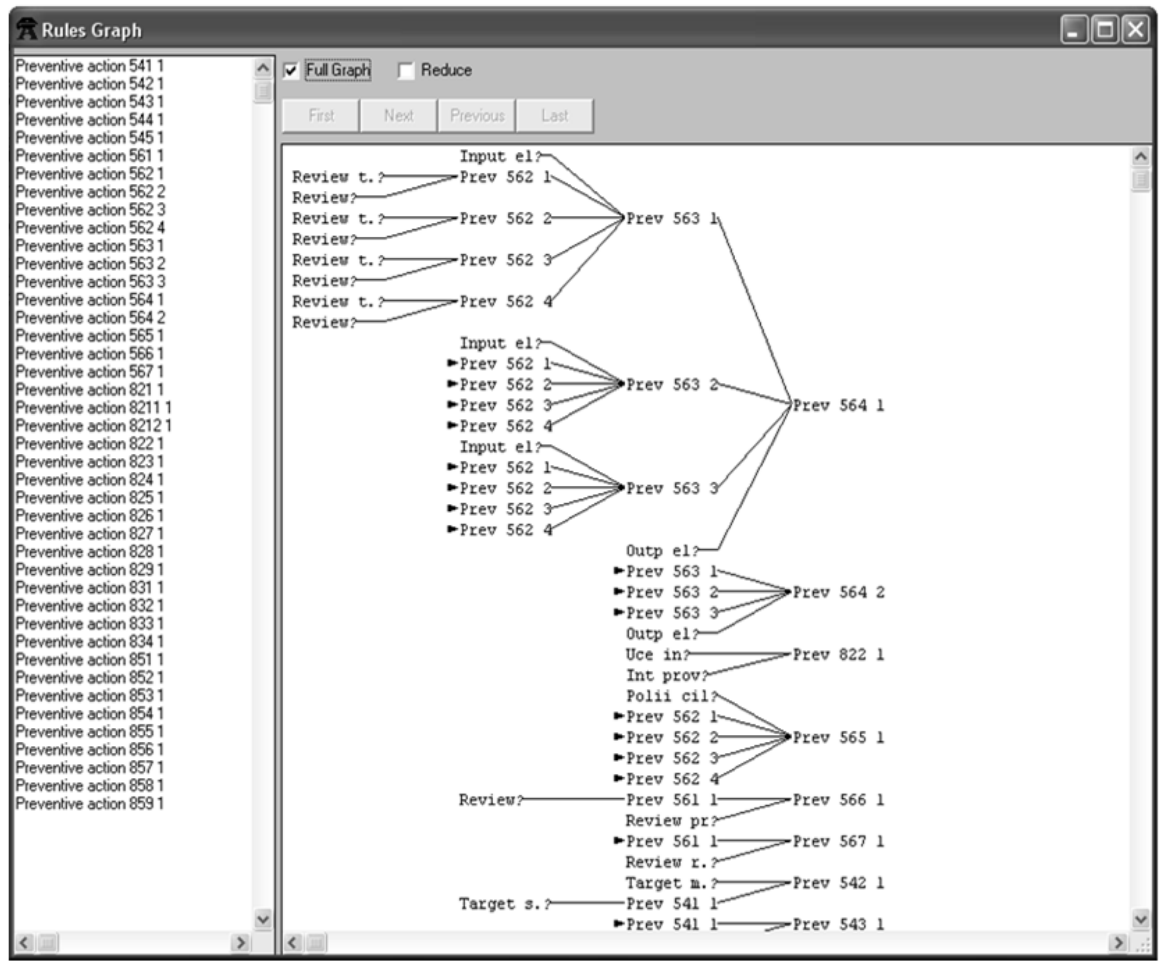

Figure 7. Decision tree

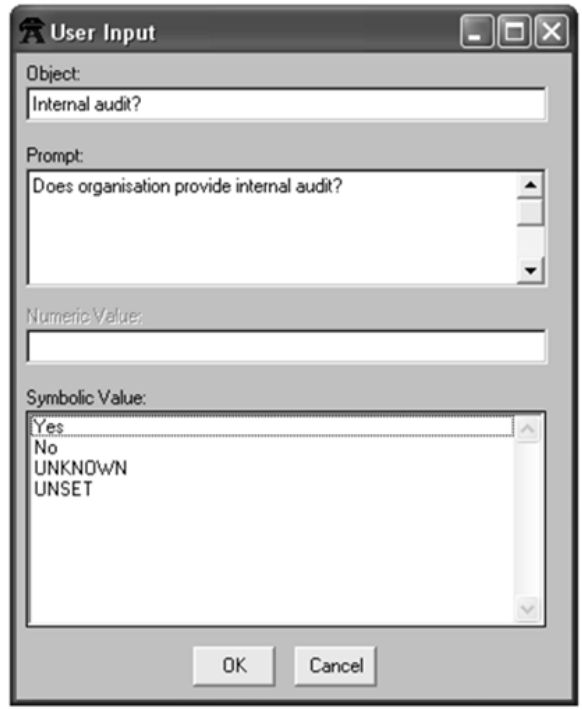

Figure 8. User's dialog box 


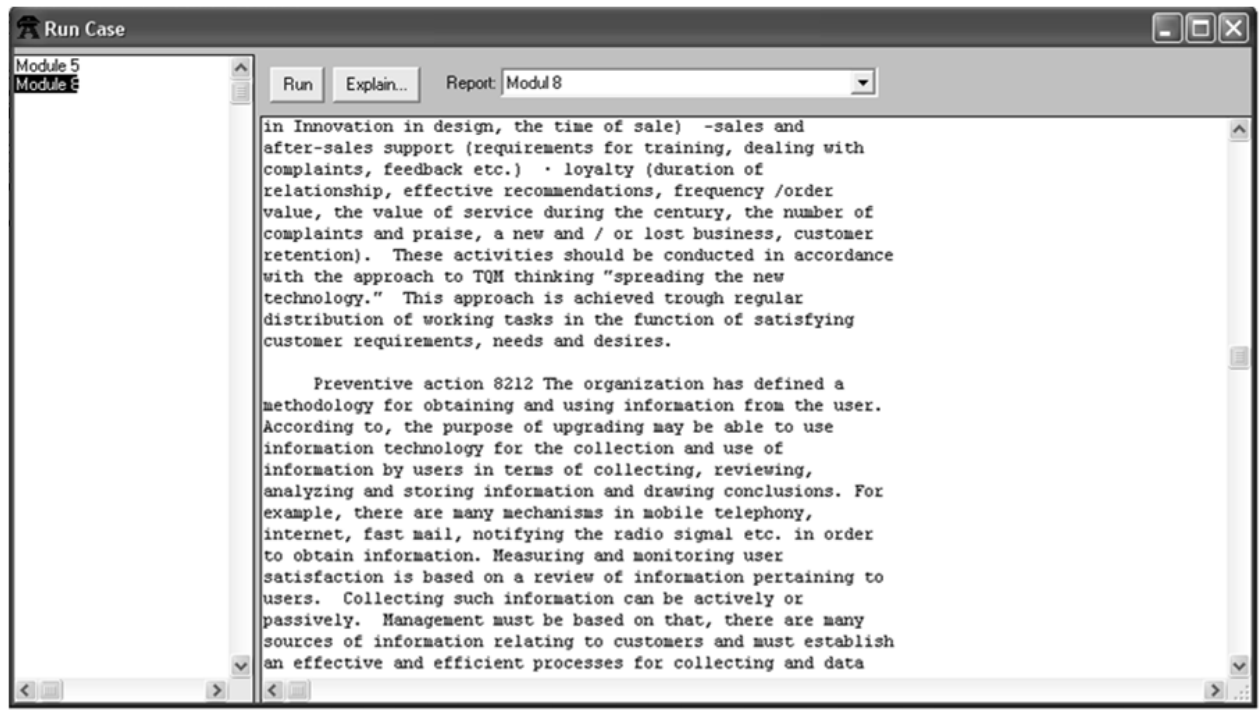

Figure 9. User's report

This expert system was developed in three iterative steps. Each of them resulted of the improvement, for example improvement of the definition of objects, set the input data, the relation between objects depending on the priorities of execution and more.

The expert system was implemented and tested in practical, real conditions in the organization that has a clear commitment to participate in the competition for the European Award for Business Excellence, also providing important measures in that direction. Evaluation was done on the basis of technical and ergonomic characteristics based on guidelines in standards ISO/IEC 9126/1:2001 for evaluation quality of software. The results are shown in Table 2.

\begin{tabular}{|c|c|c|c|c|}
\hline & Category & $\begin{array}{c}\text { Awerage } \\
\text { mark }\end{array}$ & $\begin{array}{c}\text { Awerage } \\
\text { mark }\end{array}$ & $\begin{array}{c}\text { Total awerage } \\
\text { mark }\end{array}$ \\
\hline \multirow{2}{*}{ Technical characteristic } & Fault of presented software & 8.2 & \multirow{2}{*}{8.7} & \\
\cline { 2 - 3 } & Benefit of new software & 8.7 & \multirow{2}{*}{9.2} \\
\cline { 2 - 3 } $\begin{array}{c}\text { Enfluence on job organisation } \\
\text { Enaracteristic }\end{array}$ & $\begin{array}{c}\text { General ergonomic } \\
\text { characteristic }\end{array}$ & 9.2 & \multirow{2}{*}{9.8.} & \\
\cline { 1 - 3 } & System adaptability & 9.6 & & \\
\hline
\end{tabular}

Table 2. Results of expert system evaluation

Figures showed significant high mark by categories, and thus the total amount. Software was evaluated positive in terms of technical characteristics and in terms of ergonomic. In this sense, product has small time of response, it is compatible with most used operating system, it has an excellent user's oriented interface, and it has easy data entry and a good 
view of the output, installation is simple and the software is very competitive. Also, in this sense, within the organization, it was carried out the reorganization of the priority areas from the viewpoint of improvement, implemented preventive measures for the potentially unstable areas and also applied the measures for the improvement (offered by this system) leading to business excellence achieving.

\section{Final considerations}

Nowadays, very small number (a few per cent) of the scientific research activities in area of quality management systems are based on topic of the collection and analysis of information with aim to improvement business results. That fact justify author's effort to make preventive actions for improvement business performances through establishing synergy between area of quality management and artificial intelligence like area which is strictly oriented on producing knowledge. Also, through analysis of the available software for quality management, it can be concluded that there are no any software from field of artificial intelligence that was developed for quality management systems improvement. That means that each further step in this direction brings positive scientific research results. The research point out necessity of making connection between more software solutions and tools in order to make the system with a higher level of intelligence. For this purpose, it is best to apply the integration of decision support systems and expert system. That is best world experience. With this approach it can be make system that producing knowledge and that is greatest resource which can make organization more competitive and can ensure improvement of organizations performances. Based on those facts in this research we developed unique analogy integrative approach which stays in the basis of model for improvement business process performance in the direction for achieving best organizational performances.

As the most important requests for achieving business excellences were identified requests which are mostly related to: measurement, analysis and improvement (module 8 - ISO 9001) and management responsibility (module 5-ISO 9001). The next area is most important for excellence organizational condition and at the same time area where should make very intensive action for improvement and strengthening: 821 - customer satisfaction, 72 customer related processes, 54 - planning, 85 - continual improvement, 56 - management review and 55 - responsibility, authority and communication. It is interesting to highlight, that all activities and process which is related with customer and achieving his satisfaction and anticipation his needs, are in the focus and that should be direction and guidelines for all employees.

Also, it is shown that the strengthening, especially in these areas is used to lead to the significant progress in terms of: business process reengineering, manufacturing strategy, performance measurement and benchmarking, as very important aspects of market-oriented organization.

This research present interesting and useful results which should be use for defining measurement for improvement business performance in way for achieving business 
excellence. Those results are related with term of Degree of readiness which show part (every request) of ISO 9001 certified model and they ability for achieving top business form. Also, interesting results are present through values of Coefficient of significance. This two indexes show direction about area and intensity of action which should be provide to make best organisational condition.

In organizations that have specific information through database and information systems, it is necessary to develop systems that will assist staff in decision making. These systems provide data and output information on the basis of which, in accordance with the principle of decision making base on fact, the employees make business decisions that certainly contribute to improve organizational performance. However, in the today complex business condition, organization must make stride from level of data and information to level of knowledge. That is way for ensuring prestigious position on the market. That could be achieving through development expert system base on expert knowledge and base on output of decision support system.

This approach could be related with one modern approach, which calls case base reasoning. This approach is base on experience of other companies, and that approach could be use for defining preventive action. In this sense, it can be use a system that was developed in this work. That system was testing in real condition and proved to be very useful and that showed great level of efficiency and effectiveness for real business conditions. According to process of testing and estimation, users of the system were put ratings that are present in table 2. They indicate that this system can: make financial benefits, provide better organisation of job, stimulate all employees to improving own process, synchronise function in organisation, identify priority area for improvement, define intensity of action for improvement, stimulate preventive versus corrective action, encourage better involvement of new staff in to the activities, bring higher level of flexibility and other.

\section{Author details}

Aleksandar Vujovic, Zdravko Krivokapic and Jelena Jovanovic

Faculty of Mechanical Engineering, University of Montenegro,

Department for Production Engineering, Podgorica

\section{References}

[1] Vujovic A (2008). Improvement of business processes performances based on management systems by using artificial intelligence. $\mathrm{PhD}$ thesis, University of Montenegro.

[2] Metaxios K S, Psarras J and Askounis D (2001). Expert systems in production planning and scheduling: A state-of-the-art survey. Journal of Intelligent Manufacturing, Vol. 13, No. 4, pp. 253-260.

[3] Smith A (2001). The role of tacit and explicit knowledge in the workplace. Journal of Knowledge Management, Vol. 5, No. 4, pp. 11-21. 
[4] Lang C (2001). Managerial concerns in knowledge management. Journal of Knowledge Management, Vol. 5, No. 1, pp. 43-59.

[5] Bollinger S and Smith D (2001). Managing organizational knowledge as a strategic asset. Journal of Knowledge Management, Vol. 5, No 1, pp. 8-18.

[6] Clark T and Rollo C (2001). Corporate initiatives in knowledge management. Education and Training, Vol. 43, No 4, pp. 206-14.

[7] Coff W (2002). Human capital, shared expertise, and the likelihood of impasse in corporate acquisitions. Journal of Management, Vol. 28, No. 1, pp.107-128.

[8] Jacob M (2002). Implementing formal design review. Industrial Quality Control, Vol. 23, No. 8, pp. 398-404

[9] Dommartin A (2003). ISO 9001:2000 and the EFQM excellence Model-The floor and the ceiling of the corporate house. ISO Management System, Vol. 3, No. 1, pp. 18-21.

[10] Liao S (2005). Expert system methodologies and applications - a decade review from 1995 to 2004. Expert Systems with Applications, Vol. 28, No. 1, pp. 93-103.

[11] Padhy N (2005). Artificial intelligence and Intelligent Systems. Oxford University Press: USA.

[12] Kanji K G (1998). An innovative approach to make ISO 9000 standards more effective. Total Quality Management, Vol. 9, No. 1, pp. 67 - 78.

[13] Najmi M and Kehoe F (2000). An integrated framework for post - ISO 9000 quality development. International Journal of Quality \& Reliability Management, Vol. 17, No. 3, pp. $226-58$.

[14] Mohan R and Miller D (2004). Expert systems applications for productivity analysis. Industrial Management \& Data Systems, Vol. 104, No. 9, pp. 776-785.

[15] Elmuti D (2004). World-class standards for global competitiveness: an overview of ISO 9000. Industrial Management, Vol. 38, No. 5, pp. 5-9.

[16] Srdoc A, Sluga A and Bratko I (2005). A quality management model based on the deep quality concept. International Journal of Quality \& Reliability Management, Vol. 22, No. 3, pp. 278-302.

[17] Shin M, Holden T and Schmidt A (2001). From knowledge theory to management practice: towards an integrated approach. Information Processing and Management, Vol. 37, No. 2, pp. 335-355.

[18] Kreng V and Ming Tsai C (2003). The construct and application of knowledge diffusion model. Expert Systems with Applications, Vol. 25, No. 2, pp. 177-186.

[19] Augier M and Knudsen $T$ (2004). The architecture and design of the knowledge organization. Journal of Knowledge Management, Vol. 8, No. 4, pp. 6-20.

[20] Murray J and Chao M (2005). A cross-team framework of international knowledge acquisition on new product development capabilities and new product market performance. Journal of International Marketing, Vol. 13, No. 3, pp. 54-78.

[21] ISO 9000:2005 (2005), "Quality management systems -- Fundamentals and vocabulary" International organisation for standardization, Geneva, 2005, $30 \mathrm{p}$.

[22] Zhang Z (2000). Developing a model of quality management methods and evaluating their effects on business performance. Total Quality Management, Vol.11, No.1, pp. 129 -37 . 
[23] Sun H (2000). Total quality management, ISO 9000 certification and performance improvement. International Journal of Quality \& Reliability Management, Vol.17, No.2, pp.168 - 79.

[24] Escanciano C, Fernandez E and Vazquez C (2001). Influence of ISO 9000 certifcation on the progress of Spanish industry towards TQM. International Journal of Quality \& Reliability Management, Vol.18, No.5, pp.481 - 94.

[25] Gotzamani D and Tsiotras D (2002). The true motives behind ISO 9000 certification. Their effect on the overall certification benefits and their long term contribution towards TQM. International Journal of Quality \& ReliabilityManagement, Vol.19, No.2, pp.151 - 69.

[26] Tummala R and Tang L (2003). Strategic quality management, Malcom Baldrige and European quality awards and ISO 9000 certification: core concepts and comparative analysis. International Journal of Quality \& Reliability Management, Vol. 13, No. 4, pp. 8-38.

[27] Casadesus M and Karapetrovic S (2005). An Empirical Study of the Benefits and Costs of ISO 9001: 2000 Compared to ISO 9001/2/3: 1994. Total Quality Management, Vol. 16, No.1, pp.105-120.

[28] Kosko B (1992). Neural networks and fuzzy systems: a dynamical systems approach to machine intelligence. Prentice Hall: New Jersey.

[29] Bidgoli H (1997). Modern information system for managers. Department of Management, California State University: Bakersfield-California.

[30] Welbank M (1983). A review of knowledge acquisition techniques for expert systems. Ipswich: Martlesham Consultancy Services, Martlesham, United Kingdom. 49 p.

[31] Paquin L C, Blanchard F and Thomasset C (1991). Loge-expert: from a legal expert system to an information system for non-lawyers. In Proceeding ICAIL '91 Proceedings of the 3rd international conference on Artificial intelligence and law in Oxford. St. Catherine's College: Oxford.

[32] Eppinette $M$ and Inman R A (1997). Expert systems and the implementation of quality customer service. Industrial Management \&Data Systems, Vol. 97, No. 2, pp. 63-68.

[33] Alavi, M. and Leidner D E (2001). Review: Knowledge Management and Knowledge Management Systems: Conceptual Foundations and Research Issues. MIS Quarterly, Vol. 25, No. 1, pp. 107-136.

[34] Karhu K (2002). Expertise cycle - an advanced method for sharing expertise. Journal of Intellectual Capital, Vol. 3, No. 4, pp. 430-46.

[35] Winn G, Gopalakrishnan B, Akladios M and Premkumar R (2005). Expert systems what SH\&E managers need to know about software verification and validation. Professional Safety, Vol. 50, No. 8, pp. 45-52.

[36] Comesana J and Carlos J (2002). Creating an expert system for detailed scheduling. International Journal of Operations \& Production Management, Vol. 22, No. 7, pp. 806819.

[37] Giarratano J and Gary R (2004). Expert systems: Principles and Programming-4th edition. PWS Publishing Company: Boston. 
[38] Fleet D, Peterson T and Van Fleet E (2005). Closing the performance feedback gap with expert systems. Academy of Management Executive, Vol. 19, No. 3, pp. 23-35.

[39] Relja M and Klepac N (2002). From gene to therapy- huntingtonova korea. Biochemia medica, Vol. 12, No. 1-2, pp. 35-39.

[40] Belak L, Gacina N and Radic T (2005). Food technology. In profesional material for students of High school for management in tourism in Sibenik: Sibenik.

[41] Vilber K (2002). No limits-Popular psychology. Babun: Beograd.

[42] Gilja I (2005). Prostate urinary incontinence. Medix, Vol. 11, No. 60/61, pp. 119-120.

[43] Bielawski L and Lewand R (1988). Expert systems development - Building PC based applications. John Wiley \& Sons, Hoboken: New Jersey.

[44] Elder J and Abbott D (1998). A comparison of Leading Data Mining Tools. In Knowledge Discovery and Data Mining proceedings of the Fourth international Conference in New York, Elder Reasearch: New York.

[45] Goebel M and Gruenwald L (1999). A surveyof data mining and knowledge discovery software tools. SIGKDD Explorations, Vol. 1. No.1, pp. 20-33.

[46] Oakland J (2001). Total Organizational Excellence - Achieving world class performance. Elsevier Butterworth - Heinemann: Oxford.

[47] MEST ISO 9004:2009 (2009), “Managing for the sustained success of an organization. A quality management approach", International Organization for Standardization, Geneva, 2009, p. 54.

[48] Tricker R (2006). Best Practice - ISO 9001:2000 - The Quality Management Process. Van Haren Publishing: Zaltbommel-Netherlands.

[49] FQCE (2004), "Course for auditors based on Oscar for quality award”, Fond for Quality Culture Excellence, Beograd, 2004, p.217.

[50] Perovic M (2003). Management - informatics - quality, Kragujevac. CIM Center-Faculty of Mechanical Engineering: Kragujevac.

[51] Rakovic R (2006). Quality toward business excellence. Energoprojekt - Ingraf: Beograd.

[52] Aamodt, A., and Plaza, E. (2004). Case-Based Reasoning: Foundational Issues, Methodological Variations, and System. AI Communications - IOS Press, Vol. 7, No. 1, pp. 39 - 59.

[53] Wen W, Wang W and Wang C (2005). A knowledge - based intelligent decision support system for national defense budget planning. Expert Systems with Applications, Vol. 28, No. 1, pp. 55-66.

[54] Turban E and Watson H (2008). Integrating expert systems and decision support systems. Management Information Systems Quarterly, Vol. 10, No. 2, pp. 121-136

[55] Vujica-Herzog N, Polajnar A and Tonchia S (2007). Development and validation of business process reengineering (BPR) variables: a survey research in Slovenian companies. International Journal of Production Research., Vol. 45, No. 24, pp. 58115834 .

[56] Vujica-Herzog N, Tonchia S and Polajnar A (2009). Linkages between manufacturing strategy, benchmarking, performance measurement and business process reengineering. Computers \& Industrial Engineering, Vol. 57, No. 3, pp. 963-975. 